\title{
Síndrome de superposición: lupus eritematoso sistémico y hepatitis autoinmune en una adolescente
}

\author{
An Overlap Syndrome involving systemic lupus erythematosus and \\ autoimmune hepatitis in an adolescent girl
}

Dra. Cristina Battagliottia, Dra. Daniela Rispolo Klubek ${ }^{a}$ Dr. Mario Karakachoffa y Dr. Alejandro Costaguta

\begin{abstract}
RESUMEN
La superposición del lupus eritematoso sistémico y la hepatitis autoinmune se describe ocasionalmente.

Aunque ambas enfermedades pueden compartir ciertos hallazgos, como poliartralgias, hipergammaglobulinemia y anticuerpo antinúcleo positivo, son consideradas dos diferentes. Se presenta a una paciente de 14 años con lupus eritematoso sistémico, que, luego de dos años, consultó por ictericia. Sin antecedentes de ingesta de drogas, alcohol o exposición a virus hepatotropos. Tenía un aumento de las enzimas hepáticas con anticuerpos antinúcleo, anti-ADN de doble cadena y LKM 1 positivos.

La biopsia hepática mostró una hepatitis de interfase con infiltrado linfoplasmocitario. De esta manera, cumplía con los criterios diagnósticos tanto para lupus eritematoso sistémico como para hepatitis autoinmune.

Tratada con corticoides y micofenolato mofetil, mejoró su clínica y laboratorio.

Conclusión. La hepatitis autoinmune puede ocurrir en el curso del lupus eritematoso sistémico.

Un diagnóstico temprano es importante para prevenir el avance de la enfermedad; es obligatoria la realización de la biopsia hepática.

Palabras clave: hepatitis autoinmune, enfermedades del tejido conjuntivo, lupus eritematoso sistémico.
\end{abstract}

http:/ /dx.doi.org/10.5546/aap.2016.e155

\section{INTRODUCCIÓN}

El lupus eritematoso sistémico (LES) es una enfermedad crónica, sistémica, que puede afectar múltiples órganos, que incluyen el hígado. ${ }^{1,2} \mathrm{La}$ frecuencia del compromiso hepático es baja y varía entre un $8 \%$ y un $23 \%$ según los autores. ${ }^{3-5}$

a. Hospital de Niños Dr. Orlando Alassia, Santa Fe, Argentina.

Correspondencia:

Dra. Cristina Battagliotti, cristinabattagliotti@yahoo.com.ar

Financiamiento: Ninguno.

Conflicto de intereses: Ninguno que declarar.

Recibido: 21-8-2015

Aceptado: 16-12-2015
La hepatitis autoinmune (HAI) es una enfermedad crónica, progresiva, de origen desconocido, caracterizada por la elevación de las enzimas hepáticas, hipergammaglobulinemia con presencia de autoanticuerpos y hallazgos histológicos característicos. ${ }^{6}$

Las dos enfermedades difieren, principalmente, en su fisiopatología. El LES es una enfermedad autoinmune sistémica, en la que los complejos inmunes antígenos-anticuerpos generan una respuesta inflamatoria causante del daño en diferentes órganos (no órgano específico); en cambio, la hepatitis autoinmune se caracteriza por un extenso infiltrado inflamatorio de tipo linfoplasmocitario, que es sugestivo de daño mediado por células hacia un autoantígeno (tipo órgano específico). ${ }^{2}$

Si bien son pocos los casos reportados de ocurrencia simultánea de LES y HAI, esta asociación ha sido bien documentada. ${ }^{78}$

Presentamos a una paciente de 14 años, portadora de LES, que, dos años más tarde, desarrolló HAI tipo 2.

Enfatizamos las dificultades diagnósticas que presenta la coexistencia de estas dos entidades.

\section{CASO CLÍNICO}

Se trata de una paciente femenina, caucásica, de 16 años, que, a los 14 años, desarrolló LES con nefropatía clase IV (proliferativa difusa).

Había presentado síntomas sistémicos de pérdida de peso, fatiga, anemia, alopecia, rash en alas de mariposa, exantema palmar, poliartritis con edema en los miembros inferiores y signo de Godet positivo. En el laboratorio, tenía hipergammaglobulinemia con anticuerpos antinúcleo (ANA) y anti-ADN en altos títulos con consumo del complemento.

Cumplía seis de los 11 criterios de clasificación para el diagnóstico de LES del Colegio Americano de Reumatología (American College of Rheumatology; ACR, por sus siglas en inglés - 1997).

Se inició tratamiento con ciclofosfamida endovenosa y pulsos de corticoides los primeros seis meses y se continuó con 1 gramo diario 
de micofenolato mofetilo e hidroxicloroquina para mantener la remisión junto con dosis descendentes de corticoides.

Durante el cuarto mes de haberse iniciado el tratamiento, presentó un leve ascenso de enzimas hepáticas (transaminasa glutamato-oxalacetato - glutamic oxaloacetic transaminase; GOT, por sus siglas en inglés-: $97 \mathrm{UI} / \mathrm{L}$; transaminasa glutámico-pirúvica-glutamic pyruvic transaminase; GPT, por sus siglas en inglés-: $301 \mathrm{UI} / \mathrm{L}$ ), sin signos clínicos asociados, que normalizó posteriormente.

Continuó con una buena evolución, con la negativización de la proteinuria y mejoría del laboratorio.

Dos años después, consultó por ictericia sin otro signo clínico de relevancia y elevación de enzimas hepáticas (GOT: 1480 UI/L; GPT: 1320 UI/L; Gamma-glutamil transpeptidasa -Gamma

TABLA 1: Laboratorio al inicio del lupus eritematoso sistémico y al desarrollo de la hepatitis autoinmune

\begin{tabular}{lcc}
\hline & $\begin{array}{c}\text { Diagnóstico } \\
\text { de LES }\end{array}$ & $\begin{array}{c}\text { Desarrollo } \\
\text { de HAI }\end{array}$ \\
\hline GOT (0-32 UI/L) & $40 \mathrm{UI} / \mathrm{L}$ & $1480 \mathrm{UI} / \mathrm{L}$ \\
GPT (0-31 UI/L) & $29 \mathrm{UI} / \mathrm{L}$ & $1320 \mathrm{UI} / \mathrm{L}$ \\
Bilirrubina total (0-1,10 mg/dl) & $0,56 \mathrm{mg} / \mathrm{dl}$ & $6,29 \mathrm{mg} / \mathrm{dl}$ \\
Bilirrubina directa (0-0,3 mg/dl) & $0,26 \mathrm{mg} / \mathrm{dl}$ & $5,47 \mathrm{mg} / \mathrm{dl}$ \\
Gamma GT & $72 \mathrm{UI} / \mathrm{L}$ & $214 \mathrm{UI} / \mathrm{L}$ \\
IgG & $1368 \mathrm{mg} / \mathrm{dl}$ & $1500 \mathrm{mg} / \mathrm{dl}$ \\
C3 & $14 \mathrm{mg} / \mathrm{dl}$ & $97 \mathrm{mg} / \mathrm{dl}$ \\
C4 & $2 \mathrm{mg} / \mathrm{dl}$ & $6 \mathrm{mg} / \mathrm{dl}$ \\
ANA & $+1 / 5120$ & $+1 / 100$ \\
Anti-ADN & $+1 / 640$ & $+1 / 564$ \\
ANAS & + & + \\
Anti-Ro/SSA & - & + \\
Anti-La/SSB & + & - \\
Anti-Sm & - & - \\
Anti-RNP & - & - \\
Anti-SMA & & - \\
Anti-SLA & & - \\
Anti-LKM 1 & & + \\
Anti-LC1 & & - \\
\hline
\end{tabular}

LES: lupus eritematoso sistémico; HAI: hepatitis autoinmune; GOT: transaminasa glutamato-oxalacetato;

GPT: transaminasa glutámico-pirúvica;

Gamma GT: Gamma-glutamil transpeptidasa;

ANA: anticuerpos antinucleares;

ANAS: anticuerpos antinucleares extraíbles;

Anti-ADN Anti-Ro/SSA: Anti proteína nuclear;

Anti-La/SSB: antiproteína nuclear;

Anti-RNP: antirribonucleoproteína;

Anti-Sm: antiproteína nuclear Smith;

SMA: anticuerpo antimúsculo liso;

Anti LKM1: anticuerpo antimicrosomas de hígado y riñón tipo1;

LC1: anticuerpos anticitosol hepático tipo1;

Anti-SLA: anticuerpo antígeno soluble hepático.
GT-: 214 UI/L; bilirrubina total: $6,29 \mathrm{mg} / \mathrm{dl}$; bilirrubina directa: 5,47 mg/dl); positivizó el anti-ADN de doble cadena, con caída del C4 y presencia del anticuerpo anti-LKM1 (Tabla 1).

La paciente no tenía antecedentes de ingesta de alcohol, drogas ni transfusiones previas. Los tests serológicos para virus hepatotropos, que incluyeron citomegalovirus y virus de EpsteinBarr (VEB), fueron negativos.

La biopsia hepática mostró una hepatitis crónica con infiltrado inflamatorio linfoplasmocitario periportal con hepatitis de interfase, sin fibrosis (Figura 1).

Dado que la paciente cumplía los criterios diagnósticos de HAI tipo 2, se aumentó la dosis de meprednisona a $60 \mathrm{mg}$ / día por vía oral (VO) durante un mes, con descenso progresivo en el transcurso de los meses siguientes, y se continuó con la misma dosis de micofenolato mofetilo. Presentó una rápida mejoría tanto clínica como del laboratorio y mantuvo la remisión al año de seguimiento.

\section{DISCUSIÓN}

La coexistencia del LES y la HAI, llamada síndrome de superposición u overlap, es una rara observación..$^{2-8}$

El aumento de transaminasas es un hecho frecuente en el LES, que afecta entre el $23 \%$ y el $55 \%$ de los pacientes. ${ }^{4-6}$

Este aumento es típicamente leve y, de manera probable, multifactorial, asociado, entre otros, a toxicidad por fármacos, desórdenes metabólicos,

FIGURA 1. 40 aumentos - Tinción de hematoxilina-eosina. Infltrado inflamatorio crónico, linfocitario periportal que invade el hepatocito. Hepatitis de interfase en la biopsia hepática

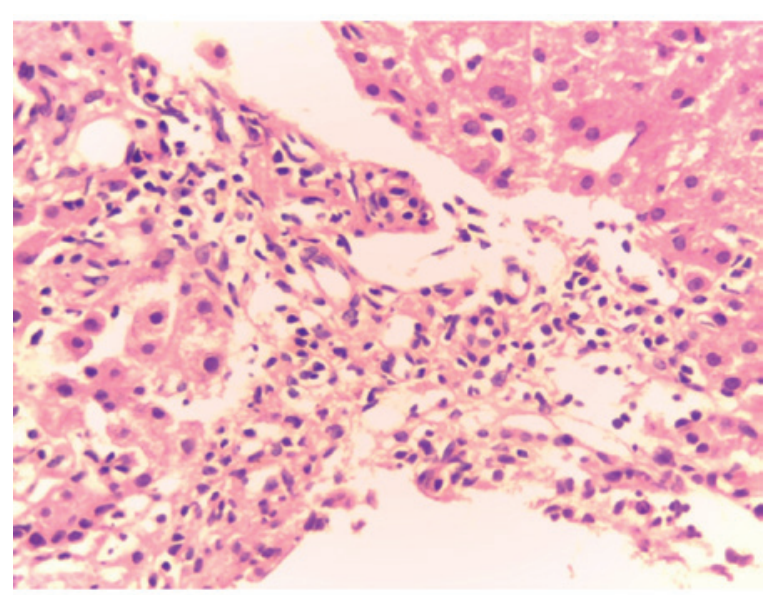


intercurrencias virales, actividad de la enfermedad o esteatosis hepática por el uso de corticoides.,

Las trombosis vasculares tanto venosas como arteriales, particularmente el síndrome de BuddChiari, deben considerarse en el diagnóstico diferencial de las hepatopatías asociadas al LES, dado el riesgo de trombofilia asociado a la presencia de anticuerpos antifosfolípidos en estos pacientes. ${ }^{4,9}$

A pesar de la alta incidencia de anormalidades enzimáticas, el compromiso clínico significativo es infrecuente, y el desarrollo de una verdadera HAI es aún menos frecuente. ${ }^{2}$ La hepatomegalia puede presentarse en un $30 \%-50 \%$ de pacientes que padecen LES, mientras que la ictericia es de rara observación, asociada a hemólisis o a infecciones superpuestas. ${ }^{2,4}$

Los pacientes que inician el LES en edades tempranas han sido relacionados con formas más graves y mayor compromiso de órganos, especialmente el riñón y el sistema nervioso, con un curso clínico más agresivo que en los adultos, pero, al igual que ellos, la afectación hepática es poco frecuente. ${ }^{7}$

Nuestra paciente con diagnóstico de LES con nefropatía a la edad de 14 años presentó fluctuaciones en las enzimas hepáticas con un compromiso clínico de ictericia y hepatomegalia leve a los dos años de haberse iniciado el LES.

Aunque verdaderas lesiones histológicas hepáticas inmunomediadas son relativamente raras en el LES, existen casos bien documentados en la literatura. Runyon et al. reportaron que 4/238 (1,7\%) de sus pacientes con LES tenían hepatitis crónica activa o cirrosis hepática. ${ }^{4}$ Series de autopsia ${ }^{10-12}$ en pacientes con LES muestran lesiones que van desde la esteatosis hasta la hepatitis periportal y llegan, incluso, a la cirrosis en el $2 \%$ de los casos.

El compromiso hepático ocasionado por la HAI, también llamada hepatitis lupoide, debe distinguirse de la hepatitis asociada al LES o "hepatitis lúpica", ya que son dos entidades diferentes, a pesar de que ambas pueden presentarse con poliartralgias, hipergammaglobulinemia y positividad para ANA. ${ }^{7}$

La HAI tipo 1 se caracteriza por presentar anticuerpos antimúsculo liso (anti-smooth muscle antibody; SMA, por sus siglas en inglés) y/o ANA. Puede tener manifestaciones extrahepáticas, que incluyen artralgias, rash malar, anemia hemolítica Coombs positiva y trombocitopenia autoinmune. ${ }^{8}$

La HAI tipo 2 está relacionada con la presencia de autoanticuerpos antihígado y riñón microsomal tipo 1 (LKM1) o anticuerpo anticitosol (LC1) y, a veces, manifestaciones autoinmunes sistémicas. ${ }^{8,9,11}$

Dentro de los hallazgos serológicos para LES activo, la positividad de los anticuerpos antiADN de doble cadena es sensible y específica. Recientemente, se describen los anticuerpos antirribosomal $\mathrm{P}$ en pacientes con grave hepatitis lúpica. ${ }^{10}$

Es importante el diagnóstico del tipo de hepatitis para ajustar el tratamiento y determinar el pronóstico, para lo cual la biopsia es obligatoria. $^{3}$

Un infiltrado inflamatorio linfoplasmocitario en los espacios portales que rompe la limitante y se extiende hacia el lobulillo es el sello distintivo de la HAI; a diferencia del infiltrado mononuclear leve en espacios porta, $y$, ocasionalmente, distribuido en el lobulillo, pero que respeta la interfase, observado en algunos pacientes con LES. Estos últimos pacientes evolucionan en forma benigna, sin progresar a la cirrosis; la lesión hepática es un epifenómeno acompañante de una reacción autoinmune más generalizada.

Nuestra paciente presentaba un cuadro histológico caracterizado por hepatitis de interfase con características de hepatitis crónica, que cumplía con los criterios para la clasificación de HAI. En ausencia de virus y otras noxas, se planteó la posibilidad de una HAI concomitante con LES.

La HAI y el LES superpuestos son una rara enfermedad, ocasionalmente descrita en la literatura. H. Oka describió 5 de 162 pacientes con HAI que cumplían criterios del ACR para LES, ${ }^{12}$ mientras que Tamai et al. reportaron 2 de 21 pacientes con hepatitis autoinmune que cumplían con criterios del ACR para LES. ${ }^{13}$

Irving et al. estudiaron la prevalencia de la enfermedad autoinmune hepática en adultos y niños con LES en una población británica. Encontraron mayor prevalencia de la enfermedad hepática autoinmune en el LES de inicio juvenil y que el compromiso hepático se manifestaba antes del desarrollo del lupus. ${ }^{14}$

Respecto del tratamiento, en la serie de casos presentada por Beisel y colaboradores ${ }^{15}$ de pacientes con LES y HAI superpuestos, cinco de ellos tuvieron buena respuesta al tratamiento inmunosupresor y presentaron remisión. Solo un paciente cuya primera biopsia mostró cirrosis desarrolló un carcinoma hepatocelular seis años después del diagnóstico de HAI. 
Nuestra paciente respondió adecuadamente al aumento de la inmunosupresión, con una rápida mejoría tanto clínica como de laboratorio, y permaneció en remisión en el seguimiento a largo plazo.

\section{CONCLUSIÓN}

La HAI puede desarrollarse en pacientes con diagnóstico de LES.

La coexistencia de ambas entidades obliga a realizar un diagnóstico preciso, apoyado, principalmente, en los hallazgos histológicos del hígado afectado.

Debe sospecharse en todo paciente con LES que presenta anormalidades crónicas persistentes de las enzimas hepáticas, con presencia de autoanticuerpos marcadores, como ANA, SMA y/o anti-LKM.

Un diagnóstico precoz es importante para ajustar el tratamiento y prevenir el avance de la enfermedad hepática.

\section{Agradecimientos}

A la Dra. María Belén Pancera y a la Dra. María Fernanda Risso del Servicio de Anatomía Patológica del Hospital de Niños Dr. Orlando Alassia por la colaboración en la selección y obtención de las imágenes de la biopsia.

\section{REFERENCIAS}

1. Wallace DJ. Gastrointestinal and hepatic manifestations. En Wallace DJ, Hahn BH, eds. Dubois' Lupus Erythematosus. $5^{\text {th }}$ ed. Baltimore: Williams \& Wikins; 1997.Págs.835-55.

2. Bessone F, Kuzmicz G. Manifestaciones gastrointestinales en el Lupus Eritematoso Sistémico. En Battagliotti CA, Gentiletti AA, Pons Estel BA, eds. Lupuseritematoso sistémico: aspectos clínicos y terapéuticos. Buenos Aires: VDB; 2013. Págs.282-97.
3. Bessone F, Poles N, Roma MG.Challenge of liver disease in systemic lupus erythematosus: Clues for diagnosis and hints for pathogenesis. World J Hepatol 2014;6(6):394-409.

4. Runyon BA, LaBrecque DR, Anuras S. The spectrum of liver disease in systemic lupus erythematosus. Report of 33 histologically-proved cases and review of the literature. Am J Med 1980;69(2):187-94.

5. MokCC. Investigations and management of gastrointestinal and hepaticmanifestations of systemiclupuserythematosus. Best Pract Res Clin Rheumatol 2005;19(5):741-66.

6. Abraham S, Begum S, Isenberg D. Hepatic manifestations of autoimmune rheumatic diseases. Ann Rheum Dis 2004;63(2):123-9.

7. Battagliotti C, Russo R. Lupus Pediátrico. En Battagliotti CA, Gentiletti AA, Pons Estel BA, eds. Lupus eritematoso sistémico: aspectos clínicos y terapéuticos. Buenos Aires: VDB; 2013.Págs.384-93.

8. Cuarterolo M, Ciocca M, Álvarez F. Hepatitis autoinmune en niños. Perspectivas actuales. Arch Argent Pediatr 2014;112(2):169-75.

9. Avcin T, Silverman ED. Antiphospholipid antibodies in pediatric systemic lupus erythematosus and the antiphospholipid syndrome. Lupus 2007;16(8):627-33.

10. ArnettFC,Reichlin M.Lupushepatitis: an under-recognized disease feature associated with autoantibodies to ribosomal P. Am J Med 1995;99(5):465-72.

11. Deen ME,Porta G, FiorotFJ, Campos LM, etal. Autoimmune hepatitis and juvenile systemic lupus erythematosus. Lupus 2009;18(8):747-51.

12. Oka H. The survey of autoimmune hepatitis in Japan. En Annual Report of Study Group on Severe Hepatitis. Tokio: Japanese Ministry of Health and Welfare; 1988. Págs. 235-41.

13. Tamai $Y$, Kin S, Ito K, Fukase M. Application of the Preliminary SLE Classification Criteria by American Rhuematism Association to autoimmune hepatitis. Ryumachi 1974;14(2):88-94.

14. Irving KS,SenD, TahirH,PilkingtonC, etal. A comparison of autoimmune liver disease injuvenile and adult populations with systemic lupus erythematosus-a retrospective review of cases. Rheumatology (Oxford) 2007;46(7):1171-3.

15. Beisel C, Weiler-Normann C, Teufel A, Lohse AW. Association of autoimmune hepatitis and systemic lupus erythematodes: a case series and review of the literature. World J Gastroenterol 2014;20(35):12662-7 